\title{
Integrating Teachers to Teach an Interdisciplinary STEM-Focused Program about Sound, Waves and Communication Systems
}

\author{
Nayif Adil Awad 1,2*, Esmael Salman 3 ${ }^{3}$, Moshe Barak ${ }^{1}$
}

${ }^{1}$ Ben Gurion University, ISRAEL

2 Sakhnin Academic College, ISRAEL

${ }^{3}$ The Arab Academic College - Haifa, ISRAEL

*Corresponding Author: awad_nayif@yahoo.com

Citation: Awad, N. A., Salman, E. and Barak, M. (2019). Integrating Teachers to Teach an Interdisciplinary STEM-Focused Program about Sound, Waves and Communication Systems. European Journal of STEM Education, 4(1), 05. https://doi.org/10.20897/ ejsteme/5756

Published: April 29, 2019

\begin{abstract}
The insufficiency of teachers who teach integrative science, technology, engineering and mathematics (STEM) courses is a major challenge facing science education today. Many teachers lack adequate expertise to combine disciplines and choose effective instructional approaches. This study examines how and to what extent teachers might succeed in teaching an innovative STEM program about a sound, waves and communication systems course in an information and communication technology-based environment. This research adopted a qualitative method to understand better the experience of three teachers who taught the course for the first time. Data collection tools included documenting mentoring meetings, observing in the classrooms and interviewing the teachers. The data were transcribed and analyzed using the content analysis method. The findings show that the teachers had only partial knowledge and, initially, even misconceptions about sound. However, their technological pedagogic content knowledge improved significantly due to the researcher's gradual but continual guidance. Four major factors contributed to the teachers' professional development: (a) dealing with innovative contents, (b) using different (advanced) teaching methods, (c) predesigning the instructional course materials and (d) offering the researcher-mentor's developmental supervision.
\end{abstract}

Keywords: STEM, sound wave, teachers' guidance

\section{INTRODUCTION}

A recent challenge for educational systems worldwide relates to preparing teachers for science, technology, engineering and mathematics (STEM) education. Numerous studies have shown that many science teachers have limited STEM knowledge and do not eagerly embrace the idea of teaching STEM content (Kim et al., 2015; Nadelson et al., 2013; Skamp and Mueller, 2001; Yates and Chandler, 2001). In addition, it is well known from the educational literature that teachers are often inclined to teach what they had learned and in the way they had been taught (Deemer, 2004; Etkina et al., 2017; Llinares and Krainer, 2006). Consequently, fostering teachers' professional development has become an essential objective in preparing STEM teachers to increase student awareness and understanding about science and technology (Augustine, 2005; National Science Foundation, 2007; van Driel et al., 2012). However, the literature on training teachers - particularly prospective teachers - for STEM education is limited. Moreover, only a few studies (Shernoff et al., 2017) have examined teachers' mentoring processes and the way those processes affect teacher professional development. The present study addresses these 
issues through the development, implementation and evaluation of a STEM-focused program about sound, waves and communication systems (SWCS) in a junior high school. It explores the effectiveness of training teachers to teach these innovative contents using the STEM approach and to examine the extent to which the guidance process may affect their professional development. We sought to identify factors that contribute to or hinder changes in teachers' knowledge, perceptions and practices.

The aim of this study was to examine and highlight the successes and problems novice teachers might encounter when teaching new STEM programs. Specifically, the study sought to answer the research questions:

1. What challenges do teachers face when teaching the SWCS program?

2. Which program factors affect teachers' professional development?

\section{LITERATURE REVIEW}

\section{STEM Education}

Education in STEM is widely recognized as national priority (Honey et al., 2014) and recent global challenges demand an interdisciplinary knowledge. Therefore, it has become imperative to combine these subjects, allowing students to connect contents and investigate issues deeply.

In K-12 settings, technology and engineering could serve a connector to engage students in integrative STEM with inquiry, problem solving and creativity. To affect such a change in schools, serious efforts are being made to transform from traditional learning approaches to STEM-focused strategies such as project-based learning. However, STEM implementation still faces several challenges, such as designing and investigating the effects of an explicit, integrated STEM program (Becker and Park, 2011) and providing teachers and educators with appropriate content knowledge in more than one (discrete) subject among the STEM subjects.

\section{Essential Knowledge to Teach Science}

Teachers play a central role in the success or failure of introducing new curricula. A program's success depends largely on teachers' knowledge, skills and experiences. Shulman $(1986,1987)$ identified seven knowledge bases needed for effective teaching. In this section, we focus on the three most important knowledge types:

- Content knowledge (CK): knowledge about the subject matter to be learned or taught.

- Pedagogical knowledge (PK): knowledge of the processes and practices or methods of teaching, including about classroom management, assessment, lesson plan development and student learning.

- Pedagogical content knowledge (PCK): knowledge about pedagogy that applies to teaching specific content. Pedagogical content knowledge differs among various content areas because it blends both content and pedagogy with the goal of developing better teaching practices in the specific content areas.

This study aims to shed light on the development (or delay) processes related to these knowledge types.

\section{Technological Pedagogical Content Knowledge for STEM Education}

In a world constantly evolving with an explosion of information and communication technologies (ICT), new technologies offer science education quick and flexible access to information, resources and experts (Williams et al., 2017). Mishra and Koehler (2006) suggested the term technological pedagogical content knowledge (TPCK) to describe knowledge essential to support intelligent uses of technology in teaching and learning, for example, to promote a student's ability to analyze and interpret data and acquire understanding of scientific concepts and spatial intelligence (Dani and Koenig, 2008; Koehler et al., 2007, 2013; Wu and Huang, 2007). However, many programs treat technology as an "add-on," isolated from the subject matter, without taking into account content-pedagogical considerations. Hence, they fail to yield a significant educational change (Angeli and Valanides, 2009).

A growing body of evidence suggests that supporting teachers with long-term professional development aimed at improving science instruction through technological support could create positive teacher and student outcomes (e.g., Bell et al., 2013). For example, Blanchard et al. (2016) reported encouraging effects of a 3-year, technologyenhanced professional development program on the beliefs and practices of 20 teachers. The teachers engaged in sustained inquiry-based experiences and used technology such as handheld probe-ware (e.g., $\mathrm{pH}$, conductivity and heart rate), graphing calculators, interactive whiteboards and data analysis software in the context of the subject matter. Similarly, Longhurst et al. (2016) described a 2-year professional development program in which teachers learned four instructional modules focused on integrating inquiry-based science instruction using technologies such as Google Docs, photo- and video-editing, 3D virtual-simulation programs and educational gaming. 


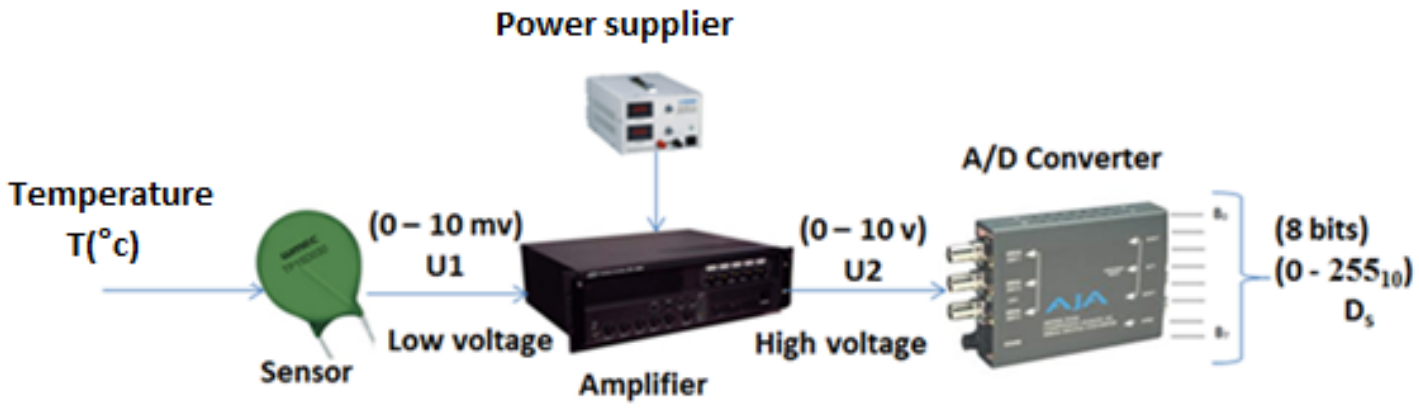

Figure 1. Sampling and analog-to-digital conversion process

\section{Essential Factors Affecting Professional Development}

Many researchers (e.g., Desimone, 2009; Eylon and Bagno, 2006; Timperley et al., 2008; van Driel et al., 2012; Vescio et al., 2008) claimed that teacher professional development programs could assist in preparing qualified teachers when these programs are long-term, comprehensive and

- treat teachers as active learners who experience significant learning processes by themselves;

- focus on classroom practice and involve teachers in instructional processes directly related to students' learning about specific content; and

- engage teachers in collaborative learning (e.g., professional learning communities and collegial interactions) where they can conduct powerful conversation and reflective dialog about curriculum and instruction.

To bring about real change in teachers' perceptions and practices, teachers should receive continuous support and pursue ongoing, life-long professional learning (Kind, 2009).

It has been widely agreed that the mentoring approach should be adapted to the teacher's needs and professional development. Based on Glickman and Carranza's (1990) work on approaches to support professional development through personalized supervision, Barak et al. (1997) described developmental supervision as comprising three stages:

1. "Show me" (directive supervision) first,

2. "Let us think together" (collaborative supervision), and then

3. "Listen to me" (nondirective supervision)

Similarly, Yerushalmi and Eylon (2013) used the customization workshop as a professional development framework to bring curricular innovations into classrooms and foster expert pedagogical problem solving. The researchers referred to three mentoring approaches: minimal guidance, maximal guidance ("spoon-fed") and cognitive apprenticeship.

\section{SOUND, WAVES AND COMMUNICATION SYSTEMS COURSE}

\section{Course Content}

The SWCS course was designed to provide junior high school students with the scientific concepts of transverse wave, longitude wave, period, frequency, wavelength, amplitude, sound velocity and sound propagation on different materials or states of matter. The relevant technological concepts and ideas focused on sound systems, microphones, speakers, amplifiers, analog-to-digital conversion and digital sound. Figure 1 describes the major phases of converting analog sound to digital sound. In addition, the students investigated advanced subjects related to sound waves through project-based learning about the Bluetooth protocol and the human ear and noise. Notably, the scientific and technological subjects were taught in an integrated fashion without formally distinguishing between science and technology.

\section{Instructional Methods}

The course was run in two rounds over three successive years. In the pilot (first round) study, the instruction consisted mainly of the teacher's theoretical presentations (20-30 minutes) and students' self-learning with simulation (45-60 minutes). In the main (second round) study, we added significant changes to the instructional methods: Besides the use of simulation and ICT, sufficient time was allocated for class discussions, practical experiments (significantly expanded in scope and diversity) and project-based learning, which were re-organized, 


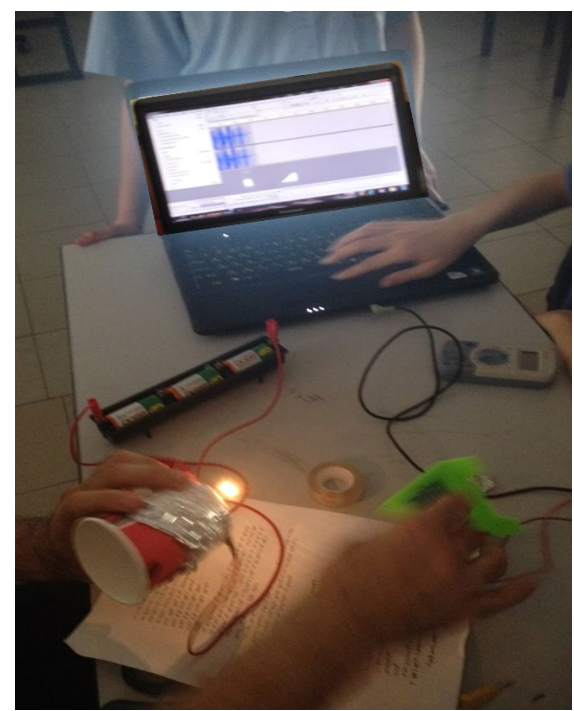

Figure 2. Recording and analyzing a sound wave by Audacity software

followed carefully by teachers and evaluated systematically. Figure 2 depicts the students' work in constructing a light-based microphone. They recorded and analyzed a sound wave using Audacity ${ }^{\circledR}$ software.

\section{Teachers' Guidance Process}

During the pilot study, the researcher met weekly with each of three teachers individually for about 1.5 hours (total of 20 hours). The most important functions of these meetings were providing the teachers with instructional materials and discussing scientific concepts such as wave, wavelength, frequency, current and voltage to ensure they comprehended the concepts well.

- During the main study, the researcher met with the same three teachers who had participated in the pilot study approximately once every 2 weeks (total of 10 hours). The meetings included:

- teacher's reflections on the last lesson, including the instruction strengths, weaknesses, difficulties and challenges;

- researcher-supported feedback according to the classroom observations;

- discussions about SWCS main concepts; and

- dialog about pedagogical matters, such as instructional methods and practices that the teachers should adopt.

\section{METHODOLOGY}

\section{Participants}

Three teachers, to whom we have given the pseudonyms Teacher 1, Teacher 2 and Teacher 3, participated in the current study. The teachers expressed high motivation to join the SWCS program and apply it in their schools, hoping such an experience will help them prepare for the coming reform in science education. The teachers met with the researcher regularly throughout the research, learned the course contents deeply and then taught it to middle (junior high) school students.

Teacher 1 was 23 years old and had studied electronics in high school. After completing a Bachelor of Science (BSc) degree in the medical lab field, he worked as a laboratory assistant in a regional medical lab and as a parttime teacher in a regional out-of-school enrichment center. He started his teaching work before completing his teaching-certificate studies, which was acceptable according to the enrichment center requirements. Teacher 1 used to teach a course in biology. His participation in this research was the first time that he taught the SWCS course.

Teacher 2 was 28 years old. He completed a Bachelor of Science (BSc) degree in physics and astronomy and taught physics for grades 7 through 10 at a comprehensive high school. Even though he lacked a teaching certificate, he had been recruited because of a lack in physics teachers in the region. Teacher 2 joined the SWCS course in his second year as a science teacher.

Teacher 3 was 56 years old and had completed a Master (MA) degree in physics. He had more than 20 years' experience teaching high school physics. Having served as the physics teaching coordinator at school, he prepared students for the 5-study unit (the highest level) physics matriculation exam. In recent years, Teacher 3 became interested in teaching physics to younger ages and taught an elementary school course he prepared about "'the 
magic of gases." " Despite Teacher 3's rich teaching experience, he has no prior knowledge in either teaching integrative STEM or applying modern pedagogical strategies.

The researcher served as mentor for the three teachers alongside to his main responsibility of conducting the research. In addition, the researcher supported the teacher's instruction in the class when needed.

\section{Data Collection and Analysis}

Data about the teachers' integration in teaching the new SWCS course were collected in both the pilot and main studies. Data collection methods consisted of

- documenting mentor meetings with each teacher and taking notes about special events, behaviors or statements that emerged;

- observing the teachers' instruction in the school and writing notes about their class work, including the extent to which they had mastered the content knowledge and used the instructional methods. Such observations were especially important to note whether the students only partially understood the contents under discussion or developed alternative ideas. The mentor attended more than $85 \%$ of the course sessions in the pilot phase and nearly half of the sessions in the main study; and

- interviewing the teachers at the end of the course. A final interview of 30-40 minutes was conducted with each teacher.

Qualitative data analysis was performed using the content analysis method, which can be conducted either inductively or deductively (Elo et al., 2014). These two content analysis processes involve three main stages: preparation, organization and reporting results. The preparation stage consists of collecting suitable data for analyzing content, finding meanings in the data and selecting the analysis units. In inductive content analysis, the organization stage includes open coding, category creation, and abstraction (Creswell and Plano, 2007; Elo and Kyngäs, 2008). In deductive content analysis, the organization stage involves developing a category matrix and examining or encoding all the data for correspondence with or demonstration of the identified categories (Polit and Beck, 2012).

In the current study, the qualitative findings, which were collected through class observations, mentor's documentations and interviews, were all analyzed using inductive content analysis that included preparation of data, recording and transcription of the interviews; re-reading the data; finding meaning in the data; and selecting meaningful content units. The data organization included open coding, creating main categories and subcategories, and reporting the results. Four main categories emerged as prominent in the data analysis: (a) course content, (b) pedagogical strategies, (c) technology and ICT use and (d) apprenticeship and mentoring. We then further divided each category into three or four subcategories.

\section{FINDINGS}

\section{Challenges Teachers Faced when Teaching the SWCS Program}

\section{Initial difficulty with subject matter}

During classroom observations in the pilot study, the researcher noticed that Teacher 1 and Teacher 2 (the two novice teachers) presented only partial explanations for, or inaccurate analogies to, the SWCS concepts. For example, Teacher 1 used analogies of tides and heartbeats to explain compression and rarefaction processes that occur when a wave propagates. Teacher 2 explained a particle's vibration in a sound wave as analogous to vibration in a swing spring or pendulum. These sorts of incorrect explanations or analogies may have led to student misconceptions. Moreover, in the middle of the course, both teachers provided incomplete answers when students asked complex questions, such as how sound travels through a telephone or mobile phone. Even Teacher 3, the experienced teacher, encountered difficulty providing simple explanations about concepts such as voltage, electrical current and energy. All three teachers had limited knowledge about technological electronic components such as resistors, diodes, transistors and their functions in an electric circuit - subjects that are usually little addressed in physics classes.

In the guidance meetings, the mentor provided the teachers with the missing knowledge and discussed with them how to explain complex concepts. Nevertheless, when in the final (pilot study) interviews the teachers were asked about difficulties they encountered in teaching the course, all three described difficulty learning new contents and imparting " unripe" knowledge to students in a short time. Teacher 3 explained:

The moment you acquire new content; you need sufficient time before you can be ready to convey it to your students. 


\section{Difficulty adopting a new pedagogical approach}

- Neither Teacher 1 nor Teacher 2 had teaching certificates, and both had limited knowledge about teaching strategies. Their lessons focused mainly on providing theoretical explanations. Teacher 3 also tended to teach in a traditional way. Although theoretical instruction was dominant in all cases, the teachers' motives seemed to vary. For example, whereas their lack of pedagogical knowledge might have played a role in the cases of Teacher 1 and Teacher 2, the regular instruction habit, and lack of motivation to change might have influenced Teacher 3's difficulty adopting a new approach.

- In the pilot study, the researcher guided the teachers to integrate class presentations with students' use of technological tools, such as simulations and instructional websites. In practice, Teacher 3 spent most of the class lesson time on theoretical presentations, and Teacher 1 and Teacher 2 devoted most of the time to students' work with computers. To summarize, we can say that despite the difference between Teacher 3 and the other teachers (Teachers 1 and Teacher 2) regarding the extent they emphasized theory and ICT components, all of them applied the lesson plans exactly as prepared by the researchers without initiating substantial changes.

- In the main study, the researcher together with the teachers designed the instructional method. They thought together about the lesson plans, paying more attention to include four elements:

- A short (15-minute) teacher presentation

- Class discussions

- Use of ICT tools

- Laboratory experiments

In addition, they designed the instruction to gradually integrate project-based learning into the course. Although the teachers still encountered several difficulties (e.g., in explaining scientific concepts regarding a physical phenomenon, choosing suitable software or carrying out lab demonstrations), their teaching and their students' learning in the class improved significantly in comparison with the pilot study, as expressed in the middle exam results in each round. In this phase, Teacher 3 managed to develop as an independent teacher showing an extent of creative initiative. On the other hand, only Teacher 2 developed as an independent teacher, whereas Teacher 1 did not show serious development. More details are described later.

\section{Program Factors that Affect Teacher Professional Development}

All three teachers expressed initial interest in joining the SWCS course as a stage in their professional development. For example, when asked at the initial meeting why he was interested in teaching the SWCS course, Teacher 1 commented:

I think it is an opportunity to learn from a veteran professional teacher [points to the researcher].... My feeling is that this course brings different methods of work and that teachers who join it will receive support and encouragement.

In the first interview, Teacher 2 explained:

It was my first year teaching physics. ... I believe that taking the SWCS course will help me learn more about teaching physics in school.

Teacher 3 discussed his desire to participate in teaching the SWCS course to focus on introducing changes in physics teaching to spark student curiosity about physics and encourage them to choose physics in high school:

I want to know more about new ways and approaches for teaching physics. ... This could help me
convince good students to major in physics in high school. ... The fact that the course is offered under
the supervision of a research university encouraged me a great deal.

\section{Acquiring pedagogical content knowledge}

Findings from classroom observations and teacher interviews showed that the teachers in this study acquired PCK by iterative processes of using pre-instructional materials, attending guidance meetings and teaching the course in the classroom. In the following section, we describe how the mentor's developmental supervision improved the teachers' knowledge and practices.

Mentor explanations and demonstrations: The "show me" phase. In the pilot study, the mentor devoted a significant part of the guidance meetings to teaching the teachers about the SWCS subjects. He adapted his instruction to each teacher's knowledge level and needs. For example, the teachers' knowledge about analog waves varied. Teacher 1 was familiar with physics concepts only technically: He pointed out the wavelength and period 


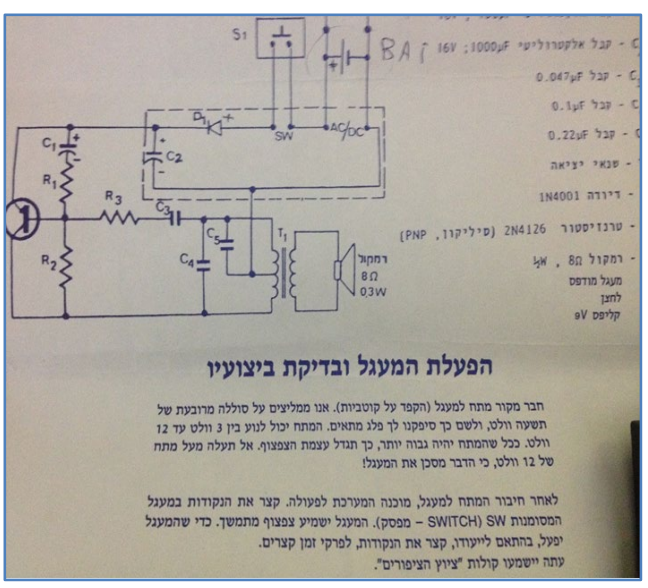

a) The system drawing

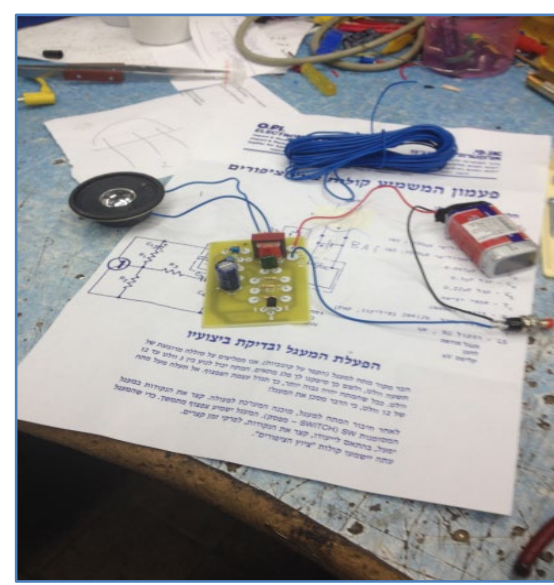

b) The system implementation

Figure 3. The electronic tweet bell

time on a graph but did not fully comprehend their meanings. The mentor used the pre-instructional materials to explain the concepts in detail. Teacher 2, who had taught tenth grade students about waves for 1 year, had partial knowledge about differences between sound and light waves or, more generally, between mechanical and electromagnetic waves. The mentor discussed with Teacher 2 how he should treat these subjects in school. Teacher 2 also had difficulty finding appropriate experiments and demonstrations and doubted his self-efficacy to carry out experiments in class. Over the course of the guidance meetings, the mentor showed him some simple experiments and explained them gradually. For example, the mentor presented the differences in covering an alarm clock and mobile phone with foil - although the alarm clock still produced a sound (at lower volume), the mobile phone showed no connection. Conversely, Teacher 3 was very familiar with the instructional materials about analog waves and was more interested in listening to the mentor's explanations. Teacher 3 commented about his satisfaction with the mentor's emphasis on promoting an "understanding" approach to teaching physics to younger children.

All three teachers asked the mentor for detailed explanations about technological subjects, such as sound amplification system, sampling, analog-to-digital conversion and digital sound. The mentor explained these subjects several times, gave examples and guided the teachers to combine their theoretical explanations with their students' use of the simulation. In addition, the mentor worked with the teachers to build an electronic tweet bell while explaining to them about the electronic circuit and the components that comprised it (Figure 3).

The classroom observations revealed that all three teachers relied on the pre-instructional materials (i.e., teacher presentations and student class activities) during their class teaching. Furthermore, in trying to imitate the mentor's explanations accurately, especially Teacher 1 and Teacher 2 (novice teachers) paid little attention to the students' understanding. However, at the end of the pilot study, the teachers expressed their satisfaction with the preinstructional materials:

\footnotetext{
It was a good idea to prepare these presentations and activities for us; without them, I might have been lost. ... In this way, I at least have a clear direction or framework. (Teacher 1)
}

Having the course materials ready gave me a lot of confidence. ... It is much easier than constructing everything by yourself. (Teacher 2)

\begin{abstract}
The prepared contents were very important...I used them although I have the knowledge. ... I cannot imagine how you can carry out research without determining the contents in advance; otherwise, every teacher would focus on different aspects. (Teacher 3)
\end{abstract}

To summarize, in the pilot study the mentor adopted the "direct or "show me" approach to guiding the teachers in order to bridge gaps in the teachers' subject matter knowledge.

Mentor and teacher discussions: The "let us think together" phase. At the beginning of the main study, the mentor considered the teachers as partners or colleagues and helped them develop gradually. In the guidance meetings, they dealt with the SWCS contents and placed special emphasis on promoting teaching strategies, especially hands-on experiments and use of ICT tools. The teachers proposed new ideas for experiments and activities and discussed them with the mentor. In addition, the mentor engaged the teachers in assessing students' understanding and examining their work. He encouraged the teachers to discuss their students' difficulties and together they thought about ways to overcome them. For example, 
- Many of Teacher 1's students were not familiar with how wire parameters, such as tension, type and thickness, affect wave progress. The mentor and Teacher 1 sought a suitable simulation, and the teacher presented it to the students.

- Many of Teacher 2's students were unable to sort out sound velocity in air, helium and nitrogen. The mentor and Teacher 2 performed an experiment in the classroom and measured sound velocity in the different gases.

In coordination with the mentor, all three teachers tried to implement the instructional model (described earlier) in their classes. Teacher 1 and Teacher 2 even used a timer to ensure that they did not exceed each activity's time limit. They adjusted their lesson plans according to insights derived from the model's implementation and shared their impressions with the mentor.

Findings from the classroom observations indicated that Teacher 1 and Teacher 2 started to move freely among the students in the class, helping them and asking questions to examine their understanding. They also became more confident to carry out real laboratory experiments on their own, conduct class discussions and insist on clear and accurate scientific explanations from their students.

In the interviews, the mentor asked the teachers whether they perceived any change in the level or manner of guidance from the pilot to the main study. All three teachers mentioned a significant change:

\begin{abstract}
In the pilot study, I felt like a student who is learning new content, while now in the main study, I am learning more about the dynamic work in the class. ... We managed to make a better connection between the guidance meetings and teaching in the class. I think that the mentor's attendance in the class contributed to this. (Teacher 1)
\end{abstract}

I felt freer and more confident in this phase...After my exposure to the course contents in the pilot study, I was ready to improve myself and improve my instruction. ... I contributed more to the discussions in the guidance meetings and worked in collaboration with the mentor. (Teacher 2)

Teachers as independent instructors: The "listen to me" phase. In the middle of the main study, the mentor began to encourage the teachers to engage in more self-work and take responsibility for teaching in the class. Two of the three teachers developed new content, suggested creative experiments not included in the original course and tried them out with their students. For example, Teacher 2 prepared a detailed presentation rich with ICT tools about electronics components that students used to construct the tweet bell. He also proposed a new experiment for sampling room temperature using the MultiLab program to demonstrate the essence of the sampling operation to the students. Teacher 3 suggested constructing a light-based microphone (in which sound causes changes in light received by a solar cell) alongside the carbon and magnetic microphones and used the Audacity ${ }^{\circledR}$ program to show the electric signals. The teachers commented on their motivations behind their actions:

It was very important to me that students not only construct the tweet bell, but also understand how the electric circuit works, as well as the contribution of each component. (Teacher 2)

We always think about carbon and magnetic microphone. I thought it would be interesting to try out an innovative idea - the light-based microphone... I feel confident enough to take this risk with my students. I was not afraid to face failure. (Teacher 3)

After approximately 9 weeks, Teacher 2 and Teacher 3 showed a high level of confidence to change lessons plans and adapt them to the students' needs. For example, when Teacher 2 discovered that some students were still unable to distinguish between concepts such as pressure and intensity or mass and weight, he immediately presented simple demonstrations to clarify the concepts. Teacher 2 and Teacher 3 also provided simplified but accurate explanations to unexpected questions the students raised regarding complex concepts such as electrical fields, magnetic fields, AC and DC currents and sampling resolution. Nevertheless, Teacher 1 still relied heavily on the basic materials the mentor had prepared, investing little effort to develop the course. Researcher-mentor discussions did not help because Teacher 1 was more committed to his work in the medical lab than to teaching.

Towards the end of the course, the mentor discussed with the teachers the factors that contributed or hindered their professional development. All three mentioned that the atmosphere of safety and support and the personal relationship with the mentor based on mutual respect contributed to the tutoring process success. Teacher 1 recommended devoting more hours to this curriculum in the future and rewarding teachers financially for participating in the program. 


\section{Attaining technological pedagogical content knowledge}

At the beginning of the current study, novice Teachers 1 and 2 thought the use of ICT tools meant merely entering an Internet website or viewing a YouTube video. The veteran teacher, Teacher 3, expressed reservations about the use of ICT tools and exhibited a somewhat negative attitude. However, the SWCS course included the use of simulations and animations to explain complicated concepts such as wave, sampling and resolution. In addition, the Audacity ${ }^{\circledR}$ software was used to manipulate sound, including recording, editing and analysis; the MultiLab data analysis program used to collect, investigate and present data in tables and graphs (e.g., it was used in the experiment presented in Figure 2); Google Sites for building new websites (e.g., to present the final project); and discussions forums to argue the course subjects after class.

The mentor guided the teacher on how to use the tools technically and use their potential to make learning about sound and waves meaningful. In addition, the mentor guided the teachers individually according to their needs and questions. For example, Teacher 2 expressed interest in using videos, and the mentor showed him how to convert static videos to dynamic, interactive videos using the Edu-Tube and Zaption websites. Teacher 3 was interested in summarizing his lessons by engaging the students in learning games, and the mentor guided him in building one in the form of "The Race to the Million."

To conclude, the mentor's contribution was crucial for integrating the use of ICT tools into the SWCS course. Without the mentor's help, the teachers might have continued their traditional teaching without integrating ICT tools. Instead, given the examples the mentor prepared and the talks he held with the teachers, they recognized the potential of educational technology and began using it.

\section{DISCUSSION AND CONCLUSION}

In this paper, we examined the guidance provided to help teachers teach a new STEM curriculum about sound waves and communication systems, and explored factors that might stimulate or hinder the process. The participants comprised three teachers, two of whom were novice teachers and one a veteran teacher with more than 20 years' experience in teaching physics. None had taught the SWCS course before the study.

In the literature review, we focused on two central aspects relevant to the current study. The first was teachers' knowledge about subject matter and their mastery in instructional strategies, based on the concepts Shulman (1987) coined as PCK -pedagogical content knowledge. Recently, the term PCK was extended to TPCK to reflect technological pedagogical content knowledge (Kohen and Kramarski, 2012). The second referred to the literature about mentoring teachers (Borko et al., 2010; Pegg et al., 2010; van Driel et al., 2012; Yerushalmi and Eylon, 2013), focusing on the notion of developmental supervision. This term expresses the idea of customizing the guidance approach to teachers' needs and professional development (Barak et al., 1997; Glickman and Carranza, 1990; Greene, 1992; Yerushalmi and Eylon, 2013).

Regarding the teachers' content knowledge at the outset of the study, the findings show that although the more experienced teacher was familiar with the subject of waves and sound, such as analog waves and amplification, he tended not to provide detailed explanations of scientific concepts such as wavelength and resonance or characterization of amplification. The two novice teachers had only partial knowledge and even a few misconceptions about sound phenomena. Moreover, all three teachers lacked knowledge about technological subjects, such as sampling, analog-to-digital conversion and digital sound.

Further, from the pedagogical aspect, all three teachers mainly used traditional teaching methods and lacked adequate practical pedagogical knowledge on how to teach using a combination of theory, lab experiments, ICT tools and project-based learning in a STEM-focused program such the SWCS course. Four factors affected the teachers' professional development in these aspects throughout the course:

- Innovative content. The SWCS course dealt with imparting new authentic topics related to sound and waves - a well-known subject from the physics field - in a new approach that combines the STEM subjects.

- Advanced instructional methods. The SWCS course imparted to teachers rich methods for science instruction that constitute state-of-the-art approaches in teaching and learning, for example, integrating theoretical teaching, lab experiments, use of ICT tools, simulation and project-based learning.

- Instruction design. The mentor prepared the initial instructional materials (e.g., theoretical presentations, lab experiments and class activities) for both the teachers and the students. These teaching and learning resources contributed to effective guidance and facilitated teaching the course in the classroom. Towards the end of the course, two teachers developed professionally and prepared new learning materials independently.

- Intensive guidance. The mentor supported the teachers throughout the course in guidance meetings and by attending the course sessions in the class. The mentor customized this guidance according to the teachers' development level and needs. He moved smoothly through a developmental supervision between the "show me," 
"let us think together," and "listen to me" approaches. Thus, the mentor observed the lessons, discussed each teacher's practices with them, listened to their reflections and provided constructive feedback.

Notably, all four components were essential to encourage teachers to initially teach and then continue the SWCS course. If any one component were missing, presumably the teachers would not have been ready to teach the course and would have spent considerable time preparing the course and getting the mentor's guidance.

Developing teachers'TPCK was critical for the program's successful implementation in the field. Nevertheless, it is worth noting that the mentor's personal guidance constituted only a partial answer to dealing with the issue of preparing STEM teachers. There remains a serious need to integrate science teachers into long-term programs that support them as they collaboratively develop their professional knowledge in groups (Borko et al., 2010). Levy (2017) suggested an example of how to address physics teaching challenges within the framework of professional learning communities. Deep discussion and exposure to the SWCS program in regional professional communities - based on the active experiences of teachers who act as learners, classroom teachers and leaders of physics teachers - could contribute meaningfully to endeavors that promote integrating teachers to teach STEM-focused programs. Therefore, to promote interdisciplinary instruction among teachers, we propose organizing professional training with specific STEM-oriented programs that emphasize aspects of contents, pedagogies and technology together, and simultaneously enable teachers to implement the principles taught with pupils in schools. In addition, we recommended establishing professional communities that combine both novice and veteran teachers in each area.

\section{LIMITATIONS AND RECOMMENDATIONS}

Three teachers participated in this study, of whom only one was qualified and experienced. The other two had a weaker background in teaching physics. The findings indicated common and different needs they had during training. However, meaningful training has the potential of contributing significantly to both. In light of the large shortage of teachers for STEM teaching, which is considered a relatively new approach, it is reasonable to assume that educational systems in different countries will invest resources to train STEM teachers of both types. This study should be extended to a larger population in order to examine the integration processes of teachers of both types. We recommend conducting future research with a larger sample of participants from more diverse populations (e.g., including both male and female teachers from different countries and cultures).

\section{REFERENCES}

Angeli, C. and Valanides, N. (2009). Epistemological and methodological issues for the conceptualization, development, and assessment of ICT-TPCK: Advances in technological pedagogical content knowledge (TPCK). Computers and Education, 52(1), 154-168. https:// doi.or.10.1016/j.compedu.2008.07.006

Augustine, N. R. (2005). Rising Above the Gathering Storm: Energizing and Employing America for a Brighter Economic Future. Washington, DC: National Academy Press.

Barak, M., Pearlman-Avnion, S. and Glanz, J. (1997). Using developmental supervision to improve science and technology instruction in Israel. Journal of Curriculum and Supervision, 12(4), 367-382.

Becker, K. H. and Park, K. (2011). Integrative approaches among science, technology, engineering and mathematics (STEM) subjects on students' learning: A meta-analysis. Journal of STEM Education: Innovations and Research, 12(5/6), 23-37.

Bell, R. L., Maeng, J. L. and Binns, I. C. (2013). Learning in context: Technology integration in a teacher preparation program informed by situated learning theory. Journal of Research in Science Teaching, 50(3), 348-379. https://doi.org/10.1002/tea.21075

Blanchard, M. R., LePrevost, C. E., Tolin, A. D. and Gutierrez, K. S. (2016). Investigating technology-enhanced teacher professional development in rural, high poverty middle schools. Educational Researcher, 45(3), 207-220. https://doi.org/10.3102\%2F0013189X16644602

Borko, H., Jacobs, J. and Koellner, K. (2010). Contemporary approaches to teacher professional development, in E. Baker, B. McGaw and P. Peterson (eds), International Encyclopedia of Education (pp. 548-555). Oxford: Elsevier.

Creswell, J. W. and Plano, C. V. L. (2007). Designing and Conducting Mixed Methods Research. Thousand Oaks, CA: SAGE.

Dani, D. and Koenig, K. M. (2008). Technology and reform-based science education. Theory into Practice, 4(3), 204211. https:// doi.org/10.1080/00405840802153825

Deemer, S. (2004). Classroom goal orientation in high school classrooms: Revealing links between teacher beliefs and classroom environments. Educational Research, 46(1), 73-90. https://doi.org/10.1080/0013188042000178836 
Desimone, L. M. (2009). Improving impact studies of teachers' professional development: toward better conceptualizations and measures. Educational Researcher, 38(3), 181-199. https://doi.org/10.3102\%2F0013189X08331140

Elo, S., Kääriäinen, M., Kanste, O., Pölkki, T., Utriainen, K. and Kyngäs, H. (2014). Qualitative content analysis: A focus on trustworthiness. SAGE Open, 4, 1-10. https://doi.org/10.1177/2158244014522633

Elo, S. and Kyngäs, H. (2008). The qualitative content analysis process. Journal of Advanced Nursing, 62, 107-115. https://doi.org/10.1111/j.1365-2648.2007.04569.x

Etkina, E., Gregorcic, B. and Vokos, S. (2017). Organizing physics teacher professional education around productive habit development: A way to meet reform challenges. Physical Review Physics Education Research, 13(1), 010107. https:/ / doi.org/10.1103/PhysRevPhysEducRes.13.010107

Eylon, B. S. and Bagno, E. (2006). Research-design model for professional development of teachers: Designing lessons with physics education research. Physical Review Special Topics-Physics Education Research, 2(2), 020106. https://doi.org/10.1103/PhysRevSTPER.2.020106

Glickman, I. and Carranza, F. A. (1990). Glickman's Clinical Periodontology. Philadelphia: Saunders.

Greene, M. L. (1992). Teacher supervision as professional development: Does it work? Journal of Curriculum and Supervision, 7(2), 131-148.

Honey, M., Pearson, G. and Schweingruber, A. (2014). STEM Integration in K-12 Education: Status, Prospects, and an Agenda for Research. Washington: National Academies Press.

Kim, C., Kim, D., Yuan, J., Hill, R. B., Doshi, P. and Thai, C. N. (2015). Robotics to promote elementary education pre-service teachers' STEM engagement, learning, and teaching. Computers \& Education, 91, 14-31. https:// doi.org/10.1016/j.compedu.2015.08.005

Kind, V. (2009). Pedagogical content knowledge in science education: Perspectives and potential for progress. Studies in Science Education, 45(2), 169-204. https:// doi.org/10.1080/03057260903142285

Koehler, M. J., Mishra, P. and Cain, W. (2013). What is technological pedagogical content knowledge (TPACK)? Journal of Education, 193(3), 13-19. https://doi.org/1177\%2F002205741319300303

Koehler, M. J., Mishra, P. and Yahya, K. (2007). Tracing the development of teacher knowledge in a design seminar: Integrating content, pedagogy, and technology. Computers \& Education, 49(3), 740-762. https://doi.org/10.1016/j.compedu.2005.11.012

Kohen, Z. and Kramarski, B. (2012). Developing a TPCK-SRL assessment scheme for conceptually advancing technology in education. Studies in Educational Evaluation, 38(1), 1-8. https:// doi.org/10.1016/j.stueduc.2012.03.001

Levy, S. (2017). Professional Development of Leading Physics Teachers in Professional Learning Community (Doctoral dissertation). Weizmann Institute of Science, Israel.

Llinares, S. and Krainer, K. (2006). Mathematics (student) teachers and teacher educators as learners, in A. Gutierrez and P. Boero (eds), Handbook of Research on the Psychology of Mathematics Education (pp. 1-18), Rotterdam: Sense.

Longhurst, M. L., Coster, D. C., Wolf, P. G., Duffy, A. M., Lee, H. and Campbell, T. (2016). Multi-year professional development grounded in educative curriculum focused on integrating technology with reformed science teaching principles. School Science and Mathematics, 116(8), 430-441. https:// doi.org/10.1111/ssm.12197

Mishra, P. and Koehler, M. J. (2006). Technological pedagogical content knowledge: A new framework for teacher knowledge. Teachers College Record, 108, 1017-1054. https://doi.org/10.1111/j.1467-9620.2006.00684.x

Nadelson, L., Callahan, J., Pyke, P., Hay, A., Dance, M. and Pfiester, J. (2013). Teacher STEM perception and preparation: Inquiry-based STEM professional development for elementary teachers. Journal of Educational Research, 106, 157-168. https:/ / doi.org/10.1080/00220671.2012.667014

National Science Foundation. (2007). A National Action Plan for Addressing the Critical Needs of the U.S. Science, Technology, Engineering, and Mathematics Education System. Available at: http://www.nsf.gov/nsb/edu_com/draft_stem_report.pdf. (Accessed 20 November 2017).

Pegg, J. M., Schmoock, H. I. and Gummer, E. S. (2010). Scientists and science educators mentoring secondary science teachers. School Science and Mathematics, 10(2), 98-109. https://doi.org/10.1111/j.19498594.2009.00013.x

Polit D. F. and Beck C. T. (2012). Nursing Research: Principles and Methods. Philadelphia, PA: Lippincott Williams and Wilkins.

Shernoff, D., Sinha, S., Bressler, D. and Ginsburg, L. (2017). Assessing teacher education and professional development needs for the implementation of integrated approaches to STEM education. International Journal of STEM Education, 4(13), 1-16.

Shulman, L. S. (1986). Those who understand: Knowledge growth in teaching. Educational Researcher, 15(2), 4-14. https://doi.org/10.3102\%2F0013189X015002004 
Shulman, L. S. (1987). Knowledge and teaching: Foundations of the new reform. Harvard Educational Review, 57(1), 1-22. https://doi.org/10.17763/haer.57.1.j463w79r56455411

Skamp, K. and Mueller, A. (2001). Student teachers' conceptions about effective elementary science teaching: A longitudinal study. International Journal of Science Education, 23(4), 331-351. https://doi.org/10.1080/09500690119248

Timperley, H., Wilson, A., Barrar, H. and Fung, I. (2008). Teacher Professional Learning and Development. Wellington, New Zealand: Ministry of Education.

van Driel, J. H., Meirink, J. A., van Veen, K. and Zwart, R. C. (2012). Current trends and missing links in studies on teacher professional development in science education: A review of design features and quality of research. Studies in Science Education, 48(2), 129-160. https:/ / doi.org/10.1080/03057267.2012.738020

Vescio, V., Ross, D. and Adams, A. (2008). A review of research on the impact of professional learning communities on teaching practice and student learning. Teaching and Teacher Education, 24(1), 80-91. https://doi.org/10.1016/j.tate.2007.01.004

Williams, P. J., Nguyen, N. and Mangan, J. (2017). Using technology to support science inquiry learning. Journal of Technology and Science Education, 7(1), 26-57. https:// doi.org/10.3926/jotse.234

Wu, H. and Huang, Y. (2007). Ninth-grade student engagement in teacher-centred and student-centred technologyenhanced learning environments. Science Education, 91, 727-749. https://doi.org/10.1002/sce.20216

Yates, G. C. R. and Chandler, M. (2001). Where have all the skeptics gone? Patterns of new age beliefs and antiscientific attitudes in preservice elementary teachers. Research in Science Education, 30(4), 377-387. https://doi.org/10.1007/BF02461557

Yerushalmi, E. and Eylon, B. S. (2013). Supporting teachers who introduce curricular innovations into their classrooms: A problem-solving perspective. Physical Review Special Topics: Physics Education Research, 9(1), 010121. https://doi.org/10.1103/PhysRevSTPER.9.010121 